\title{
Discharge against medical advice (DAMA): Causes and predictors
}

\author{
Ensieh Ashrafi ${ }^{1}$, Samin Nobakht ${ }^{2}$, Meysam Safi Keykaleh ${ }^{3}$, Edris Kakemam ${ }^{4}$, Edris Hasanpoor ${ }^{5}$, Mobin \\ Sokhanvar ${ }^{6}$
}

\begin{abstract}
${ }^{1}$ M.Sc. in Health Services Management, Shahid Labbafinejad Hospital, Social Security Organization (SSO), Tehran, Iran

${ }^{2}$ M.Sc. in Health Services Management, Department of Health Management, Tehran Science and Research Branch, Islamic Azad University, Tehran, Iran

${ }^{3} \mathrm{Ph} . D$. Student in Health in Disaster and Emergencies, School of Health, Safety and Environment, Shahid Beheshti University of Medical Sciences, Tehran, Iran

${ }^{4}$ Ph.D. Student in Health Services Management, Research Center for Modeling in Health, Institute for Futures Studies in Health, Kerman University of Medical Sciences, Kerman, Iran

${ }^{5} \mathrm{Ph} . \mathrm{D}$. Candidate in Health Services Management, Health Services Management Research Center, Institute for Futures Studies in Health, Kerman University of Medical Sciences, Kerman, Iran

${ }^{6} \mathrm{Ph} . \mathrm{D}$. Candidate in Health Services Management, Iranian Center of Excellence in Health Management (ICeHM), Tabriz University of Medical Sciences, Tabriz, Iran
\end{abstract}

Type of article: Original

\begin{abstract}
Background and aim: DAMA is a result of patient dissatisfaction, which increases the rate of readmission, mortality, and complications. In this study, the causes and predictors of DAMA in Shahid Labbafinejad Hospital of Tehran were determined.

Methods: The descriptive and analytical study was conducted in 2016 from the information of 1,168 hospitalized patients in the period of 2015 and the first half of 2016. Patients' information was collected using checklists and through clinical records, nursing unit reports, and telephone calls. The collected data were analyzed using SPSSv18 software and by employing chi-square test and logistic regression modeling.

Results: The DAMA rate was estimated at $3.27 \%$. Among the causes of DAMA, the high rates were related to personal problems $(39.04 \%)$ and going to other centers $(34.93 \%)$, and the lowest level was related to dissatisfaction with the physician (3.08\%). Age groups (19-37, OR=2.17), (38-56 years, $\mathrm{OR}=1.70)$, and (57-75, $\mathrm{OR}=1.62$ ), gender (male, $\mathrm{OR}=1.47$ ), locations (Tehran city, $\mathrm{OR}=0.61$ ) and (Tehran Province, $\mathrm{OR}=0.63$ ) were predictors of DAMA $(\mathrm{p}<0.05)$.

Conclusions: The importance of DAMA requires practical measures such as creating a suitable environment for patients, providing consulting services for youth, improving staff relations, providing assistance for patients in need, and removing accommodation problems of patients and their companions to reduce the DAMA.
\end{abstract}

Keywords: Discharge, Readmission, Iran

\section{Introduction}

Hospital clinical team members, legally and morally, are obliged to provide health care services for patients from admission until the end of the treatment process (1). However, the clinical staffs of the hospital sometimes encounter patients who refuse to continue the treatment at the hospital and leave the hospital against the advice of physicians and by their personal desire. Leaving the hospital by these patients is a challenge and concern for hospital staff and increases the risk of adverse clinical results (2); thus, the study results conducted in a year estimated the mortality rate of patients who were discharged against medical advice (DAMA) at 16\% (3). The DAMA also is one of the

\section{Corresponding author:}

Mobin Sokhanvar, Iranian Center of Excellence in Health Management (ICeHM), Tabriz University of Medical Sciences, Tabriz, Iran. Tel: +989149467336, Email: mobinsokhanvar16@yahoo.com

Received: August 15, 2016, Accepted: February 06, 2017, Published: June 2017

iThenticate screening: January 30, 2017, English editing: March 25, 2017, Quality control: May 12, 2017

(C) 2017 The Authors. This is an open access article under the terms of the Creative Commons Attribution-NonCommercialNoDerivs License, which permits use and distribution in any medium, provided the original work is properly cited, the use is non-commercial and no modifications or adaptations are made. 
leading causes of hospital readmission (4-7). The readmission rate of this class of patients would be increased for reasons such as deterioration in the patient's condition at home or cessation of the treatment before stabilization of his/her health condition (8). The results of a retrospective study, in which 181,516 admitted patients were studied during two years, showed that the risk of mortality and readmission of DAMA patients is $40 \%$ more than patients who complete their treatment period in the hospital (9). The readmission of this class of patients is different among countries; the study conducted in Canada has estimated the readmission rates about $10 \%$, while in other countries $24.4 \%$ and $3.7 \%$ were reported $(6,10-12)$. This rate in the United States was reported $0.8 \%-2.2 \%(12)$ and in Iran for the psychiatric patients was $3 \%$, and $20 \%$ for the emergency sector (13). DAMA also can increase healthcare costs of patients and the health system up to $56 \%$. A study in Australia has estimated the cost of readmission of patients about $\$ 8.6$ million per year (14). Despite the unfavorable consequences of the DAMA, the issue has become one of the most common problems in the health system. The percentage of patients who leave the hospital against medical advice, according to various conditions, is variable. A total of $2 \%$ of all patients end the treatment process against medical advice (15). In large hospitals and especially for alcoholic patients, drug addicts and people with mental health problems, this rate has been reported more than $20 \%$, in public hospitals $4 \%$, and $1 \%$ in small rural hospitals (16). In another range of studies, the rate of DAMA is estimated $0.3 \%-2.2 \%$ in public hospitals $(12,17-19)$ and higher than $25.9 \%$ in other centers $(6,9,20)$. Also, this rate in developing countries has been reported more than developed countries $(2,4,21,22)$. In Iran, the DAMA rate for children was $4.2 \%$ and for patients referred to the university hospital is obtained $8.4 \%(23,24)$. Several studies have been conducted to investigate the causes of DAMA. Dissatisfaction with the care received, an enhanced sense of well-being (16), financial problems (21, 2527), lack of access to skilled and qualified physicians, lack of advanced medical services due to lack of essential medical equipment, high burden of patients referral, and bustle in medical centers (11), dissatisfaction with the medical staff, dissatisfaction with the hospital environment, not achieving a satisfactory result from treatment (28), and prolonging the stay of patients (29) are of investigated reasons in the studies. In addition to the reasons stated, several variables have been examined in studies and have been confirmed as predictors of DAMA. Being young (3, $30)$, male gender $(15,17)$, having lack of health insurance $(11,12)$, drug addiction, alcohol, and mental health problems $(3,4)$ are of the most important predictor variables of DAMA. DAMA, on the one hand, leads to dire consequences for patients and, on the other hand, has an increased likelihood of the need for readmission, which creates increased costs for patients and the healthcare system. The results of studies conducted in Iran confirmed the high rate of DAMA and readmission due to this issue $(13,23,24)$. Investigating the current situation and also being aware of the causes as well as predictor variables can be useful in planning in order to reduce the rate of DAMA, make patients more satisfied, and improve the quality of services. Therefore, the aim of this study was to investigate the DAMA in patients referred to the Shahid Labbafinejad Hospital of Tehran as well as determining the reasons and associated predictor factors.

\section{Material and Methods}

\subsection{Study design and patients}

The present study was cross-sectional and carried out in 2016. The research environment was Shahid Labbafinejad Hospital of Tehran, which is affiliated to the Social Security Organization (SSO) and in the training field works under the supervision of Shahid Beheshti University of Medical Sciences. The hospital has an emergency, nephrology, urology, renal transplant, ophthalmology, infectious diseases, heart and lung, intensive care unit (ICU), cardiac care unit (CCU), and a respiratory care unit (RCU). Hospital bed number was 226 , and bed occupancy rate (BOR) was reported $86.4 \%$ in first half of 2016. All patients during 2015 and the first six months of 2016 who were admitted to the center have formed the study population. From 22,929 patients during the specified time interval, 752 patients left hospital against medical advice. Sampling in this study was performed in a census manner, and all patients with DAMA $(\mathrm{n}=752)$ were selected as samples. In regard with determining the affecting factors of DAMA (using logistic regression), the sample with an equal number from people who were released from hospital, according to the physician's advice, was elected in the same time frame. To synchronize the two groups (DAMA / clearance by physician); people with an equal number from the same parts and in the specified time interval were selected.

\subsection{Data collection}

The information needed to carry out the study including variables related to the patients (age, sex, marital status, insurance status, location, and hospitalization unit), as well as the reasons for the DAMA based on a research-made checklist were extracted. To access the variables related to patients, clinical records in the hospital information system were used. In cases where the information was not complete, through contact with patients, using the phone number in their cases, the lack of information was obliterated. Patients, who their information due to reasons such as 
lack of phone number and their unwillingness to respond and cooperation was incomplete, were excluded. In the second part and to determine the causes of DAMA, nursing unit forms designed for this purpose were used. Data collection for this study was done with the consent of the hospital authorities, and patients' data were gathered with their informed consent after providing the necessary explanations and answering questions.

\subsection{Statistical Analysis}

Finally, the collected data were entered into SPSS-v18 software. For reporting, the results of descriptive statistics (frequencies and percentages) were used. Also to determine the relationship between the studied variables with the type of discharge, the chi-square test was used at a 5\% confidence level. In the end, to determine the factors affecting the DAMA, logistic regression was used. In this regard, due to the lack of assumptions about the effects of different variables on predicting the type of discharge, the likelihood of backward approach (Backward: LR) was used. Also, to review the adequacy of model, a Hosmer-Lemeshow goodness-of-fit test was used.

\section{Results}

From 752 people who had left the hospital against medical advice, the full data of 584 samples $(77.65 \%$ of all DAMA patients) were collected by referring to clinical records, personal satisfaction forms in nursing units, and phone calls to patients. The DAMA rate in the studied hospital was estimated $3.27 \%$. Descriptive findings, with separation by two types of discharge are presented in Table 1 .

Table 1. Status of research variables based on the types of discharge in hospitalized patients in the hospital of Shahid Labbafinejad

\begin{tabular}{|c|c|c|c|c|c|}
\hline \multirow[t]{3}{*}{ Variable } & & \multicolumn{4}{|c|}{ Discharge type } \\
\hline & & \multicolumn{2}{|c|}{$\begin{array}{l}\text { Discharge against medical } \\
\text { advice }\end{array}$} & \multicolumn{2}{|c|}{$\begin{array}{l}\text { Discharge according to medical } \\
\text { advice }\end{array}$} \\
\hline & & $n$ & $\%$ & $n$ & $\%$ \\
\hline \multirow[t]{5}{*}{ Age (year) } & $1-18$ & 8 & 1.4 & 12 & 2.1 \\
\hline & $19-37$ & 98 & 16.8 & 127 & 21.7 \\
\hline & $38-56$ & 192 & 32.9 & 194 & 33.2 \\
\hline & $57-75$ & 201 & 34.4 & 198 & 33.9 \\
\hline & $75<$ & 85 & 14.6 & 53 & 9.1 \\
\hline \multirow[t]{2}{*}{ Sex } & Male & 276 & 47.3 & 222 & 38 \\
\hline & Female & 308 & 52.7 & 362 & 62 \\
\hline \multirow[t]{3}{*}{ Marital status } & Married & 428 & 73.3 & 417 & 71.4 \\
\hline & Single & 38 & 6.5 & 55 & 9.4 \\
\hline & Widow/Divorced & 118 & 20.2 & 112 & 19.2 \\
\hline \multirow[t]{4}{*}{ Insurance status } & No insurance & 42 & 7.2 & 32 & 5.5 \\
\hline & Social security & 295 & 50.5 & 308 & 52.7 \\
\hline & Health insurance & 148 & 25.3 & 155 & 26.5 \\
\hline & Other & 99 & 17 & 89 & 15.2 \\
\hline \multirow{3}{*}{$\begin{array}{l}\text { Place of } \\
\text { residence }\end{array}$} & Tehran City & 332 & 56.8 & 282 & 48.3 \\
\hline & Tehran Province & 82 & 14 & 74 & 12.7 \\
\hline & Other & 170 & 29.1 & 228 & 39 \\
\hline \multirow[t]{10}{*}{ Inpatient ward } & Emergency & 259 & 44.3 & 259 & 44.3 \\
\hline & Nephrology & 87 & 14.9 & 87 & 14.9 \\
\hline & Urology & 41 & 7 & 41 & 7 \\
\hline & $\begin{array}{l}\text { Kidney } \\
\text { transplant }\end{array}$ & 3 & 0.5 & 3 & 0.5 \\
\hline & Eye & 43 & 7.4 & 43 & 7.4 \\
\hline & $\begin{array}{l}\text { Infectious } \\
\text { disease }\end{array}$ & 60 & 10.3 & 60 & 10.3 \\
\hline & Heart \& Lung & 53 & 9.1 & 53 & 9.1 \\
\hline & ICU & 2 & 0.3 & 2 & 0.3 \\
\hline & $\mathrm{CCU}$ & 33 & 5.7 & 33 & 5.7 \\
\hline & $\mathrm{RCU}$ & 3 & 0.5 & 3 & 0.5 \\
\hline
\end{tabular}


As can be seen in both groups, approximately $65 \%$ of patients are in the age range of 38-75 years. The frequency of men in both groups was more than women. In terms of marital status in both groups, the highest frequency was related to married people; also, the number of people without a spouse (widowed/divorced) was more than single individuals (not married). Insurance status of patients showed that the highest and lowest frequencies are related to patients with social insurance and uninsured patients, respectively. On average, $50 \%$ of people in both groups were living in Tehran. The causes related to DAMA were extracted according to the information contained in the form completed by the nursing unit. The highest and lowest frequencies are related to personal problems (39.04\%) and dissatisfaction with the physician (3.08\%), respectively. The frequencies related to other reasons; going to other centers, tired from treatment, and dissatisfaction with care were $34.93 \%, 16.95 \%$, and $6 \%$, respectively. To study the relationship between variables with the type of discharge, the chi-square test was used. According to the results of the test, a significant relationship between the variables of age $(\mathrm{p}=0.017)$, gender $(\mathrm{p}=0.001)$, and place of residence $(\mathrm{p}=0.002)$ with the type of discharge was observed. There was no significant relationship between marital status $(\mathrm{p}=0.182)$ and insurance status $(\mathrm{p}=0.508)$ with type of discharge. The results of logistic regression to investigate the impact of independent variables on the probability of DAMA are presented in Table 2 . The adequacy of the model in this study was confirmed by Hosmer-Lemeshow goodness-of-fit test $(\mathrm{p}=0.536)$. In accordance with the results presented, there was a significant relationship between variables such as age, gender, location and the likelihood of DAMA, $(\mathrm{p}<0.05)$. The age groups $(19-37, \mathrm{OR}=2.17),(38-56, \mathrm{OR}=1.70)$ and $(57-75, \mathrm{OR}=1.62)$, gender (male, $\mathrm{OR}=1.47$ ), locations (Tehran, $\mathrm{OR}=0.61$ ) and (Tehran Province, $\mathrm{OR}=0.63$ ) were predictor factors of DAMA $(\mathrm{p}<0.05)$.

Table 2. Results of logistic regression to analyze the influence of independent variables on DAMA

\begin{tabular}{|l|l|l|l|l|l|l|}
\hline Variable & $\beta$ & SE & $p$-value & OR & \multicolumn{2}{|l|}{ CI 95\% } \\
\cline { 5 - 7 } & & & & & Lower & Upper \\
\hline 1-18 years & 0.79 & 0.56 & 0.161 & 2.22 & 0.72 & 6.77 \\
\hline 19-37 years & 0.77 & 0.25 & 0.002 & 2.17 & 1.32 & 3.56 \\
\hline 38-56 years & 0.53 & 0.21 & 0.014 & 1.70 & 1.11 & 2.60 \\
\hline 57-75 years & 0.48 & 0.21 & 0.024 & 1.62 & 1.06 & 2.48 \\
\hline Male & 0.39 & 0.12 & 0.001 & 1.47 & 1.16 & 1.87 \\
\hline Married & -0.18 & 0.16 & 0.255 & 0.83 & 0.60 & 1.14 \\
\hline Single & -0.04 & 0.31 & 0.880 & 0.95 & 0.51 & 1.77 \\
\hline No insurance & -0.29 & 0.28 & 0.305 & 0.74 & 0.42 & 1.30 \\
\hline Social insurance & 0.10 & 0.17 & 0.545 & 1.10 & 0.79 & 1.54 \\
\hline Health insurance & 0.13 & 0.18 & 0.492 & 1.13 & 0.78 & 1.65 \\
\hline Tehran City & -0.47 & 0.13 & 0.000 & 0.61 & 0.47 & 0.80 \\
\hline Tehran Province & -0.45 & 0.18 & 0.020 & 0.63 & 0.43 & 0.93 \\
\hline
\end{tabular}

\section{Discussion}

This study aimed to evaluate the DAMA in patients referred to the Shahid Labbafinejad Hospital of Tehran. Threepoint $27 \%$ of patients admitted to the hospital were discharged against medical advice. This is less than the results of the studies at Children's Hospital of Mashhad (4.2\%) (23), as well as hospitals affiliated with the Mazandaran University of Medical Sciences (8.4\%) (24). Also, the amount obtained in this study was lower than the average gained in a general hospital, which was studied in Saudi Arabia (4\%) (16). However, the amount calculated was more than the results reported in a public hospital in Spain, where only $0.34 \%$ of patients left the hospital against medical advice (18). The investigated hospital in this study is located in Tehran. For patients who are referred from other parts of the country to Tehran, it is considered the last resort of effective treatment. Therefore, having lower amounts in this study compared with the results of the studies conducted in Mazandaran University of Medical Sciences can be affected by this issue.

Further, the difference in the percentage of patients with DAMA in the present study and conducted study at Children's Hospital of Mashhad could be the result of differences in the population and setting of research. The rate of DAMA in this study was more than the study conducted in Spain. In other studies, the lower rate in lessdeveloped countries compared with developing countries, for reasons such as the socioeconomic condition of referrals, the facilities, and also management of health centers have been confirmed $(2,4,21,22)$. DAMA-related causes in this study were investigated based on supplementary nursing unit's checklists in five areas of personal problems, referring to other centers, dissatisfaction with physician, dissatisfaction with care, and treatment fatigue. 
Here, the greatest rate was related to personal problems (39.04\%) and referring to other centers $(34.93 \%)$. Because dissatisfaction with care and physician in this study have been separately investigated as reasons for DAMA, these cases are not considered as part of the personal problems, and personal problems of patients can be attributed to financial problems and the problems caused by distance. Patients referred to existing medical centers in Tehran have come from other cities of the country, as in the present study $29.1 \%$ of admitted DAMA patients have been referred from other provinces. Accommodations in Tehran because of the distance, as well as the costs, would be problematic for patients and their companions. Therefore, in this study, the distance and financial problems can be considered as the main causes of the DAMA. The results are consistent with the results of studies in Nigeria (21, 28), India (25), and Tehran (27). The distance in addition to the cost for patients can increase their willingness for DAMA. The impact of distance and non-locality of the patients on their desire for DAMA has been approved in several studies.

In this study, family problems, the need for handling personal affairs at home, concern about the situation of children, etc. are mentioned as problems of distance $(31,32)$. Several reasons could be mentioned for patients referring to other medical centers; physicians working in Tehran hospitals usually work in the public and private sectors simultaneously, and, because of the difference in tariffs, there is always willingness to transfer patients to private hospitals. The advanced medical equipment is considered as an incentive to transfer to private hospitals for patients. The training nature of the hospital and distrust of patients thereof also can be one of the effective factors in this regard. Other causes for the DAMA examined in this study include the fatigue by treatment $(16.95 \%)$, dissatisfaction with care (6\%), and dissatisfaction with the physician at a rate of $3.08 \%$. Fatigue of treatment occurs by various factors such as length of stay, patient's personal problems, and his/her dissatisfaction with the care and treatment environment (33). Another reason for DAMA is the dissatisfaction of patients with received care at the hospital. In a study conducted in Kuwait, the main cause for DAMA has been patients' dissatisfaction with the received care (29). Dissatisfaction with the physician and the medical staff also has stated as one of the causes of DAMA (11). Among the reasons for DAMA, the lowest level is related to dissatisfaction with the physician. Specialty and subspecialty centers as well as main academic centers in Tehran, on the one hand, and also advanced equipment and welfare facilities has caused the expert physicians to be settled in this city. In addition, patients' imagination is one of the determining factors in the context of their perceptions of the quality of service (34). However, the patients admitted to hospitals in Tehran, with the notion of existence of the best physicians in these centers, refer to the hospitals; thus, this assumption can be a precursor to their perception and make them evaluate the quality of medical staff in a high-level, resulting in reduced dissatisfaction toward physicians.

Among the variables examined in this study, age, sex, and place of residence have a significant relationship with the type of discharge, while for insurance status and marital status variables such a significance was not observed. Age variable in this study had a significant relationship with the type of discharge and among age groups. Concerns of children about the elderly and their desire to follow up the treatment can be the cause for low levels of DAMA in higher age groups. In the study conducted in Pakistan, the highest rate of DAMA was related to the age group or "21-30" (35). Also, a review study, which was carried out on 61 studies, shows that young age is a predictor factor of DAMA (36). The results of the study conducted at the Mayo Clinic showed that the tendency for DAMA is higher among young individuals (17). The results of the present study showed that gender has a significant relationship with the type of discharge and the DAMA rate in men was $47 \%$ more than women. As previously stated on the distance from the location as well as the financial problems, concerns about handling life as well as the financial condition of the patients can be of factors affecting DAMA, in this regard, men due to the main task of financial burden have a greater responsibility, and also men's risk-taking for not receiving the service is more than women. The results of the study conducted in America and Iran, as well as the results of the review of the existing studies have confirmed the role of gender in predicting the type of DAMA $(12,36,37)$. Another predictor variable for the DAMA is the location of patients. Patients, who come from other provinces for treatment to Tehran, despite the need to spend money and time, are faced with a series of other conditions. Entering the big and crowded atmosphere of Tehran is stressful for patients, and accommodation problems are also another effective factor in this area. Therefore, combinations of economic and psychological factors lead patients and their companions to premature discharge. This part of the research findings is consistent with the results of studies on the impact of distance on tendency for DAMA $(31,32)$. Participants in this study were from one general hospital of Tehran; therefore, findings generalized to all the hospitals across the Tehran is not possible. Despite this main limitation, this study has a great strength. The information reported in this paper will increase policymakers and hospital authority's awareness about the current situation of DAMA, its causes and predictors, so they can provide some intervention about this problem to make patients be more satisfied. 


\section{Conclusions}

Among five investigated causes of DAMA, high rates were related to personal problems and going to other centers. The logistic regression modeling showed that age groups, gender, and place of residence were predictors of DAMA. Considering the importance of DAMA, it is recommended that practical measures such as creating an appropriate environment for patients and noting their requirements, providing consulting services for youth, improving staff relations, providing assistance for patients in need, and also mitigating the accommodation problems are all necessary to reduce DAMA. Conduction complementary studies in this field on the broader setting and by applying mixed methods are the appropriate path for future research in this area.

\section{Acknowledgments:}

This study has been conducted in Shahid Labbafinejad hospital of Tehran; therefore, the authors express their gratitude to all of the authorities and staff of the hospital due to sincere cooperation. The authors received no financial support for conducting this study or publishing the findings.

\section{Conflict of Interest:}

There is no conflict of interest to be declared.

\section{Authors' contributions:}

All authors contributed to this project and article equally. All authors read and approved the final manuscript.

\section{References:}

1) Joolaee S, Hajibabaee F. Patient rights in Iran: A review article. Nurs Ethics. 2012; 19(1): 45-57. doi: 10.1177/0969733011412100. PMID: 22140178.

2) Querques J, Kontos N, Freudenreich O. Discharges against medical advice. JAMA. 2014; 311(17): 1807-8. doi: 10.1001/jama.2014.1754. PMID: 24794377.

3) Youssef A. Factors associated with discharge against medical advice in a Saudi teaching hospital. Journal of Taibah University Medical Sciences. 2012; 7(1): 13-8. doi:10.1016/j.jtumed.2012.07.006.

4) Anis AH, Sun H, Guh DP, Palepu A, Schechter MT, O'Shaughnessy MV. Leaving hospital against medical advice among HIV-positive patients. CMAJ. 2002; 167(6): 633-7. PMID: 12358196, PMCID: PMC122025.

5) Ding R, Jung JJ, Kirsch TD, Levy F, McCarthy ML. Uncompleted emergency department care: patients who leave against medical advice. Acad Emerg Med. 2007; 14(10): 870-6. doi: 10.1197/j.aem.2007.06.027. PMID: 17766732.

6) Hwang SW, Li J, Gupta R, Chien V, Martin RE. What happens to patients who leave hospital against medical advice? CMAJ. 2003; 168(4): 417-20. PMID: 12591781, PMCID: PMC143546.

7) Valevski A, Zalsman G, Tsafrir S, Lipschitz-Elhawi R, Weizman A, Shohat T. Rate of readmission and mortality risks of schizophrenia patients who were discharged against medical advice. Eur Psychiatry. 2012; 27(7): 496-9. doi: 10.1016/j.eurpsy.2011.04.009. PMID: 21705199.

8) Southern WN, Nahvi S, Arnsten JH. Increased risk of mortality and readmission among patients discharged against medical advice. Am J Med. 2012; 125(6): 594-602. doi: 10.1016/j.amjmed.2011.12.017. PMID: 22513194, PMCID: PMC3372411.

9) Fiscella K, Meldrum S, Barnett S. Hospital discharge against advice after myocardial infarction: deaths and readmissions. Am J Med. 2007; 120(12): 1047-53. doi: 10.1016/j.amjmed.2007.08.024. PMID: 18060925.

10) Ibekwe RC, Muoneke VU, Nnebe-Agumadu UH, Amadife MA. Factors influencincing discharge against medical advice among paediatric patients in Abakaliki, Southeastern Nigeria. J Trop Pediatr. 2009; 55(1): 39-41. doi: 10.1093/tropej/fmn100. PMID: 19060307.

11) Baptist AP, Warrier I, Arora R, Ager J, Massanari RM. Hospitalized patients with asthma who leave against medical advice: characteristics, reasons, and outcomes. J Allergy Clin Immunol. 2007; 119(4): 9249. doi: 10.1016/j.jaci.2006.11.695. PMID: 17239431.

12) Saitz R, Ghali WA, Moskowitz MA. The impact of leaving against medical advice on hospital resource utilization. J Gen Intern Med. 2000; 15(2): 103-7. doi: 10.1046/j.1525-1497.2000.12068.x. PMID: 10672113, PMCID: PMC1495341.

13) Sheikhmoonesi F, Khademloo M, Pazhuheshgar S. Patients Discharged Against Medical Advice from a Psychiatric Hospital in Iran: A Prospective Study. Glob J Health Sci. 2014; 6(3): 213-8. doi: 10.5539/gjhs.v6n3p213. PMID: 24762365, PMCID: PMC4825465. 
14) Henry B, Dunbar T, Barclay L, Thompson R. Self-discharge against medical advice from northern territory hospitals. Darwin: Charles Darwin University. 2007.

15) Ibrahim SA, Kwoh CK, Krishnan E. Factors associated with patients who leave acute-care hospitals against medical advice. Am J Public Health. 2007; 97(12): 2204-8. doi: 10.2105/AJPH.2006.100164. PMID: 17971552, PMCID: PMC2089112.

16) Al Ayed I. What makes patients leave against medical advice? Journal of Taibah University Medical Sciences. 2009; 4(1): 16-22. doi: 10.1016/S1658-3612(09)70077-0.

17) Alfandre DJ. "I'm going home": discharges against medical advice. Mayo Clin Proc. 2009; 84(3): 255-60. Elsevier. doi: 10.1016/S0025-6196(11)61143-9. PMID: 19252113, PMCID: PMC2664598.

18) Duñó R, Pousa E, Sans J, Tolosa C, Ruiz A. Discharge against medical advice at a general hospital in Catalonia. Gen Hosp Psychiatry. 2003; 25(1): 46-50. doi: 10.1016/s0163-8343(02)00253-0. PMID: 12583928.

19) Lorenzi E, Da Cas R, Lorenzoni L, Massaria G, Aparo U. [Characteristics of voluntarily discharged patients: some reflections and a proposal]. Ann Ig. 2000; 12(6): 513-21. PMID: 11235508.

20) Onyiriuka AN. Discharge of hospitalized under-fives against medical advice in Benin City, Nigeria. Niger J Clin Pract. 2007; 10(3): 200-4. PMID: 18072444.

21) Okoromah CN, Egri-Qkwaji MT. Profile of and control measures for paediatric discharges against medical advice. The Nigerian postgraduate medical journal. 2004; 11(1): 21-5. PMID: 15254567.

22) Alebiosu C, Raimi T. A study of hospital patients' discharge against medical advice in the Ogun State University Teaching Hospital, Sagamu, Nigeria. Nigeria Medical Practitioner. 2001; 40: 33-5.

23) Ebrahimipour H, Meraji M, Hooshmand E, Nezamdoust F, Molavi-Taleghani Y, Hoseinzadeh N, et al. Factors Associated with Discharge of Children from Hospital Against Medical Advice (AMA) at Doctor Sheikh Pediatric Hospital (DSPH) in Mashhad: 2011-2013. World Journal of Medical Sciences. 2014; 11(2): 196-201. doi: 10.5829/idosi.wjms.2014.11.2.84165.

24) Karimi SA, Saravi BM, Farahabbadi EB, Zamanfar D, Fallah M, Abokheily MA. Studying the Rate and Causes of Discharge Against Medical Advice in Hospitals Affiliated to Mazandaran University of Medical Sciences. Mater Sociomed. 2014; 26(3): 203-7. doi: 10.5455/msm.2014.26.203-207. PMID: 25126018, PMCID: PMC4130680.

25) Naderi S, Acerra JR, Bailey K, Mukherji P, Taraphdar T, Mukherjee T, et al. Patients in a private hospital in India leave the emergency department against medical advice for financial reasons. Int J Emerg Med. 2014; 7(1): 13. doi: 10.1186/1865-1380-7-13. PMID: 24568343, PMCID: PMC3975965.

26) Adefemi SA, Adeleke IT, Gara P, Ghaney OOA, Omokanye SA, Yusuf AMJ. The rate, reasons and predictors of hospital discharge against medical advice among inpatients of a tertiary health facility in North-central Nigeria. American Journal of Health Research. 2015; 3(1-1): 11-6. doi: 10.11648/j.ajhr.s.2015030101.12.

27) Roodpeyma S, Hoseyni SA. Discharge of children from hospital against medical advice. World J Pediatr. 2010; 6(4): 353-6. doi: 10.1007/s12519-010-0202-3. PMID: 20549419.

28) Eze B, Agu K, Nwosu J. Discharge against medical advice at a tertiary center in southeastern Nigeria: sociodemographic and clinical dimensions. Patient Int. 2010; 2: 27-31. doi: 10.2147/pi.s11337.

29) El Malek VA, Alexander S, Al Anezi F. Discharge against Medical Advice among Children Admitted into Pediatric Wards at Al-Jahra Hospital, Kuwait. Kuwait medical journal. 2014; 46(1): 28-31.

30) Tawk R, Freels S, Mullner R. Associations of mental, and medical illnesses with against medical advice discharges: the national hospital discharge survey, 1988-2006. Adm Policy Ment Health. 2013; 40(2): 12432. doi: 10.1007/s10488-011-0382-8. PMID: 22057857.

31) Katzenellenbogen JM, Sanfilippo FM, Hobbs MS, Knuiman MW, Bessarab D, Durey A, et al. Voting with their feet-predictors of discharge against medical advice in Aboriginal and non-Aboriginal ischaemic heart disease inpatients in Western Australia: an analytic study using data linkage. BMC Health Serv Res. 2013; 13: 330. doi: 10.1186/1472-6963-13-330. PMID: 23962275, PMCID: PMC3765140.

32) Wright L. "They just don't like to wait"-A comparative study of Aboriginal and non-Aboriginal people who did not wait for treatment or discharged against medical advice from rural emergency departments: Part 1. Australasian Emergency Nursing Journal. 2009; 12(3): 78-85. doi: 10.1016/j.aenj.2009.05.005.

33) Ingram C, Wessel J, Courneya KS. Women's perceptions of home-based exercise performed during adjuvant chemotherapy for breast cancer. European Journal of Oncology Nursing. 2010; 14(3): 238-43. doi: 10.1016/j.ejon.2010.01.027. PMID: 20236860.

34) Sadiq Sohail M. Service quality in hospitals: more favourable than you might think. Managing Service Quality: An International Journal. 2003; 13(3): 197-206. doi: 10.1108/09604520310476463. 
35) Hayat AA, Ahmed MM, Minhas FA. Patients leaving against medical advice: An inpatient psychiatric hospital-based study. J Coll Physicians Surg Pak. 2013; 23(5): 342-6. doi: 05.2013/JCPSP.342346. PMID: 23673174.

36) Brook M, Hilty DM, Liu W, Hu R, Frye MA. Discharge against medical advice from inpatient psychiatric treatment: a literature review. Psychiatr Serv. 2006; 57(8): 1192-8. doi: 10.1176/appi.ps.57.8.1192. PMID: 16870972.

37) Bahadori M, Raadabadi M, Salimi M, Ravangard R. Discharge against Medical Advice: A Case Study in a Public Teaching Hospital in Tehran, Iran in 2012. Glob J Health Sci. 2013; 5(6): 179-85. doi: 10.5539/gjhs.v5n6p179. PMID: 24171886, PMCID: PMC4776885. 